\title{
A UNIVERSIDADE DA MODERNIDADE NOS TEMPOS ATUAIS
}

\author{
Elisabete Monteiro de Aguiar Pereira*
}

Recebido em: 10 de agosto de 2008

Aprovado em: 12 de dezembro de 2008

\begin{abstract}
* Professora titular da Faculdade de Educação da Universidade Estadual de Campinas. Tem experiência na área de Educação, com ênfase em Teoria Geral de Planejamento e Desenvolvimento Curricular, atuando principalmente nos seguintes temas: educação, problemas humanos, formação universitária, capacitação docente e currículo de universidade. Está na Coordenação do GEPES - Grupo de Estudos e Pesquisas em Educação Superior. E-mail: eaguiar@unicamp.br
\end{abstract}

Resumo: Analisamos neste artigo o surgimento da universidade denominada "moderna”, as funções e papéis a ela atribuídos ou dela esperados, a crise desse modelo nos tempos atuais e alguns dos elementos que estão caracterizando a universidade contemporânea. A instituição que se constituiu como "universidade moderna” teve origem na organização da Universidade de Berlim, em 1808. Passados dois séculos, podemos afirmar que as formulações de Humboldt, bem como seus pressupostos mais gerais, são ainda tomadas como relevantes. No entanto, seus princípios têm sido negligenciados ou substituídos por outros menos nobres. Na atualidade, que podemos caracterizar como sendo um período denominado pós-moderno, discute-se um novo projeto para a universidade que possa lhe permitir continuar sendo uma importante instituição do tempo presente.

Palavras chave: Universidade moderna. Projeto de universidade. Universidade contemporânea. Educação superior. Instituição de educação superior.

\section{THE MODERN UNIVERSITY IN CURRENT TIMES}

\begin{abstract}
This article analyses the emergence of the modern university, the roles attributed to or expected from it, the crisis of this model in current times and some of the elements that characterize the contemporary university. The institution that was constituted as the "modern university" has its origin in the organization of the University of Berlin, in 1808. After two centuries, we can affirm that the formulations of Humboldt, as well as its more general presuppositions, are still relevant. However, its principles have been neglected or substituted for less noble ones. Presently, a period which we can characterize as post-modern, a new project for the university has to be discussed in order for it to continue to be an important institution for our time.
\end{abstract}

Key words: Modern university. University project. Contemporary university. Higher education. Higher education institution.

\section{Introdução}

A instituição que se constituiu como "universidade moderna" teve origem na organização da Universidade de Berlim, em 1808, e tem no famoso texto de Humboldt (1997) "Sobre a Organização Interna e Externa das Instituições Científicas Superiores em Berlim" a reflexão mais significativa e concisa sobre a universidade. Podemos afirmar que o significado dessa formulação para a época 
moderna é comparável ao significado que as universidades de Paris, Oxford e Cambridge tiveram para a Idade Média. Passados dois séculos, podemos afirmar que as formulações de Humboldt, bem como seus pressupostos mais gerais, são ainda tomadas como relevantes quando a questão da universidade é discutida, embora seus princípios sejam ainda tomados como válidos, têm sido negligenciados e/ou substituídos por outros menos nobres quando se busca traçar a função das atuais instituições universitárias.

Para discutir sobre a origem do que se tornou a instituição universitária da modernidade trazemos para a consideração esses princípios que embasaram o projeto e o modelo da universidade moderna. Ao buscarmos o diálogo com esse projeto e ao trazermos para consideração as questões postas por ele, não queremos enfatizar um retorno a um ideal de universidade, mas circunstanciar que alguns desses princípios foram sendo alterados ao longo do processo histórico da universidade, outros não foram verdadeiramente implementados e outros, ainda, são extremamente atuais e permanecem relevantes para a universidade do século XXI, apesar desta estar situada num tempo histórico que apresenta grandes questionamentos aos parâmetros que instituíram a própria modernidade.

\section{Universidade Moderna: uma Nova Instituição para um Novo Tempo}

O projeto da universidade moderna se estrutura de forma a ser diferente de tudo o que se constituía universidade até aquele tempo. Surge em um período histórico onde a ciência já se despontava como o aspecto estruturante do mundo moderno e os ditames epistemológicos rigidamente controlados pela igreja já não detinham a força que teve durante os dez séculos anteriores. A Revolução Industrial que se processava, particularmente na Inglaterra, tinha aclarado a nova direção do mundo. Deixar de considerar os avanços que a ciência prometia era recusar às possibilidades de futuro para qualquer nação. No entanto, o lócus da produção científica não estava sendo considerado na instituição universitária em outros países europeus. O caráter inovador dado a essa instituição pode ser verificado na afirmação que seu mentor, Humboldt, faz em 1808 (1997, p. 93):

Nos países estrangeiros, ainda não se conhece uma universidade segundo o modelo alemão, cujo valor somente agora principia a ser reconhecido. Reconhecimento que também ocorre na Alemanha, especialmente nas regiões que não possuem universidades, ou 
mesmo numa época ainda não dominada por um espírito mais livre e flexível.

O conceito de universidade como Humboldt o concebeu, implicou essencialmente duas tarefas: "De um lado, promoção do desenvolvimento máximo da ciência, de outro, produção do conteúdo responsável pela formação intelectual e moral" da nação (p. 79). Com isso, ele deixa claro que esta nova instituição "se caracteriza pela combinação de ciência objetiva e formação subjetiva" (p. 79) e aponta que são necessárias duas condições: a interna, do esforço do indivíduo, e a externa, vinda da estrutura e do financiamento. Caracterizando o que a universidade deveria promover, Humboldt é explícito ao afirmar que sua finalidade é o enriquecimento moral da Nação e do indivíduo.

Os princípios traçados por ele estabeleceram-se como aqueles que toda universidade deveria sustentar para o bem público e o da nação. Embora tenha desenvolvido um projeto de universidade que, ao mesmo tempo, se adequava ao novo tempo e se projetava para além dele, o projeto como planejado teve pouca existência. Paradoxalmente, este projeto é a referência mais difundida e defendida de universidade moderna. O outro modelo, o modelo francês, embora tenha tido grande influência em vários países europeus e latino-americanos, nunca foi tido como um modelo de excelência científica ou moral, pela ênfase utilitarista que encerra.

Os princípios essenciais postulados por Humboldt - de forma geral, até hoje defendidos como formulações que dão à universidade seu caráter próprio - são essencialmente: a formação através da pesquisa; a unidade entre o ensino e pesquisa; a interdisciplinaridade; a autonomia e a liberdade da administração da instituição e da ciência que ela produz; a relação integrada, porém autônoma, entre Estado e Universidade; a complementaridade do ensino fundamental e médio com o universitário.

A partir desses princípios a universidade se diferenciou, e se diferencia, de outras instituições de ensino superior que não os sustentam, pois há entre elas uma diferenciação de concepção, estruturação e finalidade. O que caracterizou a universidade, chamada agora de moderna, é essencialmente a associação programática entre ensino e pesquisa. O terceiro elemento do tripé, a extensão, apareceu mais tarde, com o modelo da universidade norte-americana. No Brasil, a caracterização de uma instituição como universidade considerando os três elementos do tripé (ensino, pesquisa e extensão), foi instituída somente a partir da Reforma Universitária de 1968, na Lei nº 5.540/68. 
Apesar de ser uma forte referência, o modelo alemão não é o único entre as universidades do mundo ocidental que se constituíram como instituição da modernidade. Elas são classificadas em duas correntes principais: as idealistas e as funcionalistas, como tão bem as caracterizou a obra de Dréze e Debelle (1983).

Temos, na concepção idealista, uma visão para a missão da universidade que ainda persiste quando se fala em "idéia de universidade" e é ainda bastante defendida como a verdadeira idéia de formação universitária. Esta concepção fundamenta-se: no postulado de uma educação geral voltada para o desenvolvimento do intelecto; na unidade do ensino e da pesquisa com um corpo docente criador e um corpo discente integrado a este; na liberdade acadêmica para que a pesquisa seja a busca da verdade - um verdadeiro direito da humanidade - em toda parte, sem ser constrangida pelas forças de poder da sociedade; e, nas normas de organização estrutural, curricular e administrativa emanadas do interior da universidade.

A concepção funcionalista via outros propósitos para a universidade e outra forma de vinculá-la à sociedade e ao governo. Via a missão da universidade voltada para as necessidades sociais, com a função de servir a nação e a finalidade de ser de utilidade coletiva, sociopolítica e socioeconômica. Nesta concepção, a universidade é tida principalmente como uma instituição instrumental de formação profissional e de formação política. É o modelo desenvolvido na França e nos países socialistas. Suas normas são emanadas do exterior, sua autonomia é relativa e seu controle pelas forças de poder é preponderante.

A diferença entre essas duas matrizes da universidade moderna está caracterizado principalmente na forma de estruturá-las. No projeto de Humbold, a autonomia e a liberdade foram os princípios determinados como os mais importantes. Ele definiu tanto o entendimento como a extensão da autonomia que a universidade deveria ter. Justificava que essa autonomia tinha que ser total, desvinculada de qualquer força externa, pois concebia a universidade como uma instituição acima dos interesses do Estado, da religião ou de qualquer outro poder político ou econômico (como é o caso de termos agora as determinações do mercado de trabalho). A universidade, para ele, é o local onde a verdade deve ser buscada sem "qualquer constrangimento" (HUMBOLD, p. 197). Defendia enfaticamente que a autonomia é um princípio que ultrapassa os limites da universidade e alcança o bem da nação. Só uma universidade livre e autônoma poderia, para ele, ser capaz de dar as contribuições que a ciência pode prestar para o desenvolvimento da nação e de seus cidadãos. Assim, a universidade deveria ter liberdade didática, científica, administrativa e financeira. 
A produção da ciência através da pesquisa é vista no projeto humboldtiano como a atividade própria da universidade por ser essencialmente uma "descoberta intelectual" e menos uma "exaustiva reunião e posterior classificação de dados" (p. 84). Para Humboldt, essa forma de fazer ciência a descaracteriza de seu conteúdo intelectual e afasta os cientistas das reais finalidades da ciência.

Uma vez que, a ciência tem como principal característica a eterna busca e o desenvolvimento da ciência é tarefa essencial da universidade, essa relação fez com que, a partir dessa época, o estabelecimento de universidades fosse tomado como de fundamental importância para o desenvolvimento moral, científico e tecnológico de qualquer nação. Essa vinculação e a importância que a universidade assumiu a partir desse entendimento serão as defesas e as razões para a organização de universidades em países que buscavam, e buscam, o desenvolvimento científico e tecnológico. No entanto, a compreensão de que nesse desenvolvimento o essencial é a atividade intelectual nem sempre será tomado. Em muitos casos, a atividade científica vai perder seu conteúdo cultural e intelectual para ser mais pragmático e utilitarista.

A pesquisa no projeto de Humboldt estava na universidade porque ele a pensou em relação dialética com o ensino, unindo professores e alunos com o propósito de cultivar a ciência. Acreditava que, através desse processo, estudantes e professores eram estimulados a pensar a partir de princípios fundamentais, desenvolvendo a reflexão crítica e a criatividade, promovendo o desenvolvimento do conhecimento e novas soluções para os problemas da sociedade humana. Essa relação é o que essencialmente diferencia a universidade de outras instituições de educação superior. A diferenciação dessas instituições está bastante clara nas palavras de Humboldt (1997, p. 80-81):

Outra característica destas instituições [universidades] é que, para seus membros, a ciência é compreendida como um problema que nunca pode ser totalmente resolvido. Portanto, a pesquisa se transforma num esforço infinito. Pelo contrário, na escola, a tarefa da instituição se limita à transmissão de conhecimentos previamente estabelecidos. Já numa instituição científica superior, o relacionamento entre professores e alunos adquire uma feição completamente nova, pois, neste ambiente, ambos existem em função da ciência.

Tendo alcance menos extenso que a universidade, outras instituições que compõem a educação superior não se estruturam para a produção de ciência e limitam-se à transmissão de conhecimentos prontos, o que as tornam instituições superiores voltadas para a formação de profissionais e incapazes da produção. 
O que as dinamiza não é uma vinculação com a ciência, com a vida intelectual, mas com o ensino profissional.

No projeto humboldiano, o desenvolvimento do aspecto científico era entendido como análogo ao desenvolvimento do aspecto moral dos indivíduos, e os dois se voltavam para o bem público da nação. No entanto, ao longo do tempo, a ênfase curricular das instituições universitárias passa a enfatizar mais o aspecto científico que o moral, particularmente em países denominados "em desenvolvimento", onde a defesa da necessidade do avanço científico e tecnológico é vista mais como necessidade econômica e menos como um aspecto de constituição moral e cultural de seu povo. Perde-se, com isso, o ponto essencial da razão do desenvolvimento da ciência como visto por Humboldt, que é "formar uma consciência moral" para transformá-la em princípio de ação (p. 84).

No Brasil, são raras hoje as instituições de educação superior com um programa que, de fato, vincule o ensino com a pesquisa. Mesmo naquelas em que essa vinculação é defendida, freqüentemente essa vinculação é dificultada por um corpo docente pouco engajado com o desenvolvimento de pesquisas, quer seja por falta de verba ou por corte desta. O que temos na grande maioria das universidades brasileiras é uma "universidade de ensino" apenas, que, embora possa desempenhar um papel importante para o país, não é legitimamente "uma universidade de ensino e pesquisa."

A pesquisa é considerada de tal importância, que Humboldt argumenta ser injusto limitar as universidades ${ }^{1}$ ao ensino e à divulgação da ciência e postula que, para os professores, o fazer ciência é uma forma de avançar em suas áreas de conhecimento, pois sem ela caberia a eles apenas repetir conhecimentos produzidos em outro lugar. Para tanto, defende que o ensino não deve ser uma sobrecarga que inviabilize a pesquisa. O objetivo de Humboldt foi o de tornar a universidade uma academia - lugar onde, na Alemanha, era desenvolvida a pesquisa - e fazer, do docente, um acadêmico.

No sistema universitário brasileiro isso nem sempre foi muito bem esclarecido e equalizado. Em algumas instituições a possibilidade de fazer pesquisa ficou, e ainda fica, mais centrada em algumas áreas e, até mesmo, em alguns professores, por razões diversas, como: a importância que a área assume no projeto científico e tecnológico do País; a maior possibilidade de financiamento; a valorização da área; a possibilidade de contar com estrutura, equipamentos e pessoal técnico de apoio, com a formação do professor em nível de doutorado e seu interesse por pesquisa. Consideramos que o art.57 da LDB (Lei nº 9.394/96),

1 Afirma que "na Alemanha de seu tempo, as ciências foram muito mais desenvolvidas por professores universitários do que por membros de Academias.” (HUMBOLDT, 1997, p. 91) 
regulamentando o mínimo de oito horas semanais de atividade docente, seja uma normatização que, embora estabeleça o "mínimo" de horas, possa amparar o professor no seu interesse em desenvolver pesquisa. Consideramos, também, que essa é uma condição necessária, mas não suficiente.

A questão da busca da autonomia ao longo da história das universidades no mundo teve conquistas e retrocessos conforme o tempo histórico, político e econômico de cada país. De forma geral, podemos dizer que a luta pela autonomia e liberdade é intrínseca à defesa dos projetos de universidades. No Brasil podemos afirmar que, embora a autonomia tenha constado dos projetos de universidades brasileiras como os projetos da UDF², USP e UnB, ela de fato nunca existiu, por questões dos regimes políticos centralizados que se seguiram no tempo em que os projetos foram desenvolvidos. Acompanhando as legislações e as políticas universitárias brasileiras, vemos que a autonomia esteve presente nos textos legais como letra e direito, mas a estruturação da nossa universidade sempre teve uma organização centralizada nas instâncias governamentais, particularmente em relação aos aspectos financeiro, administrativo e curricular. Quanto às questões didáticas, podemos reconhecer períodos de maior liberdade e outros de maior centralização, notadamente nos períodos de ditadura Vargas e Militar.

Hoje, acreditamos que a luta pela autonomia da universidade, em qualquer país, seja mais delicada ainda por envolver a busca de autonomia em relação a interesses de toda sorte: econômicos, políticos, corporativos (de docentes e discentes); de grupos locais e regionais; de grupos nacionais e internacionais; de grupos minoritários ou excluídos; e até mesmo de área e disciplina. O limiar entre a autonomia e a defesa de interesses internos e externos à universidade é tênue. Essa questão já havia sido mencionada por Humboldt (1997, p. 87), ao afirmar: "a autonomia fica ameaçada não apenas pelo Estado, mas também pelas próprias instituições quando, ao assumirem determinada orientação, impedem a emergência de qualquer outra."

O princípio da liberdade, análogo ao da autonomia, é igualmente enfático no projeto humboldtiano onde há a defesa de que o "Estado não pode exigir das instituições científicas superiores nada que se relacione imediata ou diretamente a si mesmo" (p. 88). Quando se trata da pesquisa, no projeto humboldtiano a liberdade é apresentada como uma colaboração livre e contínua entre cientistas de diferentes disciplinas, cujo estimulo é a própria ciência, sem ter que obedecer a uma finalidade prévia ou a uma força exterior. No caso do Estado, o projeto da universidade moderna entende que este deve respeitar a lógica interna da

2 Universidade do Distrito Federal 
ciência, e intervir cada vez menos, pois "uma teoria equivocada sempre acarreta conseqüências práticas que são negativas para o andamento dos negócios do Estado, já que nenhuma atividade estatal pode dispensar a reflexão.” (p. 84)

Um outro princípio que é bastante claro no projeto da universidade moderna, mas pouco explorado a partir daí, é a sua constituição como uma instituição com a característica de interdisciplinaridade. A referência a esta é marcada em várias passagens, embora o termo "interdisciplinar" não seja utilizado. O que fica expresso é a forma de inter-relação das áreas e disciplinas, no ensino e na pesquisa, como característica própria e intrínseca da instituição denominada universidade.

A ênfase na interdisciplinaridade tem tido uma constante ultimamente, de tal forma que Casper (1997, p. 51) acredita que sua defesa "já atingiu o duvidoso status de um lugar comum", embora afirme que o processo de busca de novos conhecimentos nas ciências naturais, sociais e humanas demonstra a arbitrariedade e o anacronismos dos limites da "disciplinarização" do conhecimento.

A própria pesquisa tem, no projeto humboldtiano, a interdisciplinaridade como elemento constitutivo, e é nesse sentido que Humboldt enfatiza ter a organização interna das instituições científicas superiores o dever de propiciar e preservar uma colaboração contínua entre cientistas de diferentes disciplinas. O objetivo dessa cooperação é o de estimular a própria atividade de pesquisa; por isso, deve ser uma colaboração livre, isto é, sem ter que obedecer a uma finalidade prévia ou externa. "A atividade intelectual somente progride quando há cooperação, e não apenas para que um investigador forneça o que falta ao outro, mas para que o êxito de sua atividade entusiasme o próximo." (HUMBOLDT, 1997, p. 80)

O princípio da formação geral do estudante, entendida como preparação necessária para ele elevar-se "à ciência" foi explícito no projeto de Humboldt, e tomado por muitas universidades européias e norte-americanas, mas pouco implementado pelas universidades espanholas, portuguesas e latino-americanas. Por "ciência” Humboldt tinha em mente um conhecimento mais aprofundado: "o conhecimento precisa ser assimilado de tal modo que o entendimento, o saber e a criação intelectual adquiram relevância em virtude de sua precisão, harmonia e beleza internas, ao invés de ser valorizado devido a motivações externas à atividade científica." (p. 90)

Humboldt argumenta que essa é uma preparação que não se dispersa em conhecimentos isolados e sugere como denominador comum de todas as disciplinas, a ênfase na formação em humanidades dada por uma Faculdade de Filosofia. 
Podemos perceber a estreita relação deste aspecto com a forma interdisciplinar de desenvolvê-lo, ou seja, não se desenvolve a formação geral através de conhecimentos isolados. Humboldt tinha a convicção de que esse tipo de preparação levaria a um nível de comprometimento e esforço intelectual próprios aos estudantes que procuram na formação universitária algo mais que a simples preparação para uma atividade prática.

Por causa dessa observação, muitos críticos consideram o modelo humboldtiano de universidade como o de uma universidade de elite, relacionada mais a uma classe econômica do que a uma elite intelectual. Outros, no entanto, vêem a relação com uma elite intelectual e defendem que apenas esta se interessa pelo esforço e comprometimento que a sistematização científica exige. A importância da formação geral, para esses críticos, é justificada por Casper (1997, p. 43), "os alunos aprendem a pensar a partir de princípios fundamentais, devendo encontrar novas soluções.”

As transformações científicas, econômicas e políticas das diferentes nações introduziram, ao longo desses dois séculos, modificações no plano institucional da universidade de modelo humboldtiano, na sua função, no seu currículo e nos seus métodos de ensino. O surgimento de novas disciplinas que reclamavam espaços no currículo; a ênfase na prática demandando um ensino mais aplicado e menos intelectualizado; a defesa de uma mais direta relação com o tempo presente e com a sociedade mais próxima, resultou na fragmentação quase completa da concepção de universidade caracterizada como “universidade moderna”. A falta de uma unidade que a pudesse identificar levou Clark Kerr (1982), nos anos de 1970, a usar o termo "multiversidade"

O modelo humboldtiano tornou-se clássico, e o afastamento desse modelo — ou mesmo a existência de poucas instituições que o implementaram — não impede que se veja na literatura da área da educação superior o reconhecimento das suas principais teses e princípios. Casper (1997), nos anos em que foi Reitor da Universidade de Stanford - USA, escreveu um instigante texto denominado "Um mundo sem universidades?", em que, analisando os princípios da universidade moderna, indaga se essas teses e princípios são ainda pertinentes no mundo contemporâneo ou se nos aproximamos de uma época em que as universidades, como as pensou Humboldt, não mais desempenharão um papel significativo, pois são outras as demandas que a elas são feitas.

Vemos que, hoje, a universidade é solicitada a responder uma multiplicidade de expectativas tão díspares, quanto díspares são os grupos que apresentam a

3 No livro Os usos da universidade, C. Kerr (1982) esclarece que não cunhou o termo "multiversidade”, apenas o utilizou. 
demanda. Ao lado das atividades de ensino e pesquisa que, em si, já demandam um complexo de atividades, uma série infinita de solicitações é imposta a ela: contribuir na esfera pública; liderar o processo de desenvolvimento do país; acelerar o ritmo das inovações; favorecer o aperfeiçoamento das condições sociais; estimular uma melhora para a qualidade de vida da população; colocar-se à disposição da indústria, da economia e das agências sociais; gerar fundos para o financiamento de suas atividades; fazer parcerias com empresas para o desenvolvimento de projetos externos; favorecer soluções científicas e tecnológicas para os problemas da sociedade local, regional e nacional; atender as novas clientelas discentes e adaptar-se a elas; oferecer cursos de educação continuada; etc.

Para Casper (1997), mesmo as universidades com projetos claros quanto à sua missão dificilmente resistem a tantas pressões oriundas de demandas externas a elas, o que as faz modificarem seus principais propósitos a cada dia que a pressão de um determinado grupo se faça mais dominante. Analisa que tal pressão e a dispersão que esta acarreta são, atualmente, um fenômeno universal.

Não nos surpreende que, diante de tantas solicitações e da impossibilidade da universidade de atendê-las, seja dito que a universidade está em crise. Sempre que uma instituição deixa de atender a algumas das expectativas, é reconhecido o seu estado de crise. O mais interessante é notar que as análises da crise na universidade tomam como parâmetro o modelo humboldtiano de universidade moderna.

\section{A Crise da Universidade Moderna}

Segundo a hoje já clássica referência feita por Santos (1994, p. 166), a crise da universidade é gerada na tensão problemática de três domínios de contradição, sendo a primeira delas entre a produção de alta cultura para a formação das elites e a produção de padrões culturais médios e de conhecimentos úteis para a força de trabalho qualificada exigida pelo desenvolvimento industrial. Esta crise, para Santos, manifesta-se como "crise de hegemonia". A segunda contradição é entre hierarquização e democratização e apresenta-se como "crise de legitimidade"; e a terceira, entre autonomia institucional e produtividade social, revela-se como "crise institucional”.

Santos trabalha longamente na análise da manifestação dessas três crises, sempre relacionando-as ao modelo que instituiu a universidade moderna. É em Gramsci que vai buscar o conceito explicativo da mais ampla e longa crise 
da universidade, a da hegemonia que, para ele, compreende as demais e se manifesta ao ser contestada a exclusividade dos conhecimentos produzidos, reproduzidos e ensinados pela universidade. Para Santos, o início da crise de hegemonia pode ser identificado no período do "capitalismo liberal" que vigorou durante o século XIX. Vinculada a esta, a crise de legitimidade explicita-se ao ser questionada a destinação social da formação e da produção/reprodução de conhecimentos pela academia no período do "capitalismo organizado", que se estendeu do final do século XIX aos anos de 1950. A crise de legitimidade começou nos anos que se seguiram à II Guerra Mundial e intensificou-se na década de 1960. A terceira crise, a de autonomia, iniciada durante o período que o autor chama de "capitalismo desorganizado", pôs em questão a independência da universidade para organizar-se para o exercício de suas funções.

Por outro lado, Goergen (2005, p. 12) analisa que o momento atual da crise universitária caracteriza-se em três dimensões: a crise conceitual, que se refere ao conceito de universidade, em que o termo é usado genericamente por diferentes instituições; a crise contextual, em que a universidade se sente perplexa frente às dinâmicas e profundas transformações sociais; e a crise textual, que abrange "os textos internos da universidade, seus conteúdos, suas formas de ensino, sua relação com a ciência e a tecnologia, com os sentidos éticos e sociais daquilo que faz ou deixa de fazer".

As dimensões da crise da universidade, como postas pelos diferentes autores, analisadas no contexto brasileiro ficam sem sentido, pois não se pode falar em crise conceitual quando no Brasil não houve clareza sobre a instituição universidade e os três ${ }^{4}$ (ou quatro ${ }^{5}$ ) projetos de criação de universidade brasileira (UDF, USP e UnB) tiveram pouco tempo de existência, da forma como planejados. Hoje a legislação da educação superior normatiza, em termos quase exclusivamente quantitativos, o que pode ser denominado por universidade e quase nada define em termos de sua missão, como expressa o art. 52 da LDB:

Art. 52. As universidades são instituições pluridisciplinares de formação dos quadros profissionais de nível superior, de pesquisa, de extensão e de domínio e cultivo do saber humano, que se caracterizam por:

I - produção intelectual institucionalizada mediante o estudo sistemático dos temas e problemas mais relevantes, tanto do ponto de vista científico e cultural, quanto regional e nacional;

4 Comumente referimo-nos aos projetos da UDF, USP e UnB.

5 Quando se fala em um quarto projeto de universidade, inclui-se o projeto da Universidade Estadual de Campinas-Unicamp. 
II - um terço do corpo docente, pelo menos, com titulação acadêmica de mestrado ou doutorado ${ }^{6}$;

III - um terço do corpo docente em regime de tempo integral.

Discorrendo sobre a crise da universidade brasileira em nossos dias, Ristoff (1999) também encontra três dimensões: a crise financeira, a crise do elitismo e a crise de modelo.

Quanto à crise financeira, defende que o investimento em educação tem uma relação direta com ganhos em receita tributária, ou seja, o investimento em educação - notadamente em educação superior - tem retornos consideráveis na economia. Apresenta cálculos econômicos do investimento americano em educação superior, demonstrando que para cada dólar investido há um retorno entre um dólar e treze centavos a dois dólares.

No Brasil, no entanto, a educação superior é tomada como custo, e não como investimento, e essa forma de vê-la impede o aumento em seus recursos. " $\mathrm{O}$ país está hoje tão obcecado pela idéia de eficiência e corte de gastos públicos que se tornou incapaz de atentar para o retorno social, educacional e mesmo financeiro que o investimento em educação representa" (RISTOFF, 1999, p. 23). Embora a afirmação do autor tenha sido feita na década passada, em que o governo era criticado por ser neoliberal, a mudança de mãos e de orientação, infelizmente, não alterou a situação dos recursos para a educação superior.

A crise do elitismo é apresentada por Ristoff como uma crise quantitativa, com referência à pequena porcentagem de jovens na faixa de 18 a 24 anos que estão freqüentando a educação superior. Para ele, o Brasil ainda concebe a universidade como um espaço para alguns poucos privilegiados, mas precisa romper com esse círculo e "engajar-se de forma clara num programa nacional que promova o acesso amplo das populações hoje excluídas.” (1999, p. 26)

O sistema brasileiro pode ser caracterizado como de elite, se tomarmos em consideração a classificação que Martin Trow (1973) estabeleceu, com base em números e porcentagens, para caracterizar o sistema de educação superior de um país, quanto a seu atendimento à população na faixa de idade de dezoito a vinte e quatro anos. Quando a educação superior de um país atinge apenas até quinze por cento dessa população, o sistema de oferta é caracterizado como de elite, pois é ocupado principalmente por jovens da classe alta. Tendo a oferta alcançado quarenta por cento dos jovens, o sistema pode ser classificado como de massa, ou seja, com essa porcentagem os jovens atingidos não são somente

6 Esta porcentagem vai ser alterada, se o anteprojeto de reforma universitária for aprovado no Congresso. 
os da classe economicamente privilegiada. Se, porém, o alcance for maior que cinqüenta por cento, estará caracterizada uma educação superior de sistema universal, como nos países mais desenvolvidos (Inglaterra, EUA, Canadá, Austrália) e alguns da América Latina, como a Argentina.

A crise de modelo evidencia-se pela diversidade de interesses de grupos sociais: os jovens de classe média e baixa, em especial os que pertencem aos grupos excluídos, buscam a educação superior como forma de ascensão social; o Estado pretende que a universidade auxilie no desenvolvimento da ciência e da tecnologia; e as empresas desejam pessoal profissional qualificado. Para Ristoff (1999), a crise de modelo é o grande desafio hoje em países como o Brasil, em que é preciso adaptar um sistema extremamente elitista às demandas populares por acesso ao ensino superior, sem destruir as poucas boas universidades existentes. $\mathrm{O}$ autor propõe uma discussão para que a educação superior se desenvolva em diferentes instituições e não só na universidade.

A crise da universidade, para Schwartzman (1980), não é uma crise circunstancial, um mero problema de falta de meios, mas uma crise profunda de objetivos e metas. Para ele, muitos dos antigos ideais, cuja realização se pretendia através da universidade, continuam sendo importantes, mas devem ser buscados por outros meios, e dessa revisão de perspectivas deve surgir uma nova agenda para a universidade, com discussões voltadas a aspectos como:

a) democratização e cidadania, com o objetivo, em longo prazo, de eliminar o prêmio que a sociedade paga à escolarização formal, de tal maneira que seja o conteúdo da educação, e não o título, o que importe;

b) liberdade de ensino e experimentação, cujo objetivo seria a própria eliminação da idéia de "nível" com sua conotação hierárquica, e posterior substituição pelo conceito de qualidade e tipo;

c) controle de qualidade e desburocratização, que tende a agudizar ainda mais o problema que integra o quadro geral de um sistema de ensino hierarquizado, burocratizado e orientado para a busca de credenciais;

d) diferenciação das funções da universidade, com diferenças de enfoque entre educação geral, educação profissionalizante, educação de elite em poucas instituições de excelência, ênfase da pesquisa predominantemente na pós-graduação, distinção entre pós-graduação acadêmica e pós-graduação profissional.

Schwartzman (1980, p. 18) analisa que a nova agenda supõe, também, uma revisão profunda do papel do Estado no que se refere à educação em geral e à 
universidade em particular. Na sua forma de ver, a relação entre o Estado e o sistema educacional tem sido usualmente distorcida por uma falsa polaridade entre estatização, burocratização e padronização, por um lado, e privatização, flexibilidade e pluralidade, por outro. Apesar de a educação superior não poder deixar de ser promovida e sustentada primordialmente pelo Estado, Schwartzman entende que isto não deve implicar necessariamente os vícios da estrutura napoleônica, nem aqueles de uma estrutura empresarial.

Na realidade, o sistema universitário hoje no Brasil combina o pior dos dois mundos: por um lado, um sistema altamente controlado, burocratizado e enrijecido; por outro, um predomínio de instituições de ensino privado, que primam pela baixa qualidade e custos crescentes para os estudantes. (p. 19)

Outra consideração feita sobre a crise da universidade moderna diz respeito às noções de cultura e de Estado não mais como centro organizador. A mais forte razão para isso são as modificações sofridas pelo Estado Nação e, com este, o objetivo de formação dos sujeitos para a noção de cultura. É nesse sentido que algumas das análises sobre a missão e a função da universidade atual entendem a necessidade de uma revisão do modelo humboldtiano (ROCHA, 1997; THAYER, 1996). Para elas, tanto o Estado Nação quanto o conceito de cultura perderam sua antiga relevância e, estando o projeto de Humboldt baseado nessas noções, seus princípios encontram-se ultrapassados.

Além dessa relação, acredita-se que a análise da crise deva passar ainda pela consideração de que a universidade moderna tem sua configuração e seus princípios iniciados em dois marcos anteriores a Humboldt: em Kant, com O Conflito das Faculdades (1798), e na Revolução Francesa (1788).

Kant (1993), em sua obra, dá início e substrato à produção dos discursos alemães de Fichte, Schleirmacher, Schelling e Humboldt sobre a Universidade de Berlim. Estes acatam as proposições kantianas de que a universidade moderna está circunscrita sobre o conflito do saber instituído e a investigação filosófica que interroga as condições desse saber. Além deste, o outro conflito se dá no antagonismo entre a idéia de uma universidade especulativa e a idéia de uma universidade profissional.

No Conflito das Faculdades, publicado pela primeira vez em 1798, Kant articula as categorias que - contra os limites das universidades medievais - vão marcar a arquitetura dessa nova instituição. As categorias apresentadas por Kant são: Estado, povo, verdade, linguagem, reflexão, determinação, autonomia, história e progresso (KANT, 1993). Assim, falar em crise do sistema universitário 
moderno é analisar as aproximações e as distâncias da arquitetura transcendental das categorias kantianas. Thayer (1996, p. 44) aponta que "quando se fala de crise da universidade moderna, se fala da incapacidade total ou parcial do quadro categorial kantiano". Sua análise apresenta também "a impossibilidade de qualquer metarrelato que possa dar conta do saber na atualidade". Mais enfaticamente o autor afirma que "as categorias modernas (Estado, povo, língua, autonomia, reflexão, verdade, história, progresso) perderam seu poder representativo e referencial."

A influência da Revolução Francesa potencializou o espírito cartesiano nas ciências naturais, humanas e no mundo político e moral. A universidade napoleônica seria cartesiana, tecno-profissional e guia crítico-espiritual do Estado (moderno) e reafirmaria a ilustração francesa através de uma universidade estatal de ensino, regida pelo interesse do Estado para o progresso econômico-político do Estado e da divulgação da língua nacional.

A crise que se discute, desde então, tem a ver com as contingências e a quebra de limites e de categorias daquilo que se constituiu a "arquitetura" da universidade moderna.

Casper (1997) tem uma leitura inversa e sugere que é precisamente porque essas noções se enfraqueceram que se podem reler as formulações humboldtianas com olhos livres. Lyotard (1989, p. 54) analisa que a "função primordial da universidade moderna foi a elaboração de metarrelatos legitimadores da relação entre a ciência, a nação e o Estado" e que, por meio destes, o saber tornava-se cúmplice de um projeto de fortalecimento do Estado Nação, particularmente no modelo napoleônico. Sabemos pela história das universidades que o propósito da Universidade de Berlim foi o de ser oposta à inclinação utilitarista francesa e ao uso desta como instrumento do Estado, o que subordinava o saber especulativo aos interesses prático-técnicos.

Assim, a concepção alemã da vinculação entre universidade e Estado é oposta à francesa. Os alemães concebiam o princípio especulativo da ciência e da filosofia como princípio de Estado, isto é, concebiam a construção do Estado como efeito do espírito filosófico, do espírito especulativo, livre e crítico. Já na educação superior francesa, a filosofia era concebida como espírito ideológico do Estado. Lyotard (1989, p. 70) chama a atenção para essa ênfase de Humboldt para a vinculação da universidade com o Estado, dizendo que, para os proponentes da Universidade de Berlim, "interessa não o conhecimento, mas o caráter e a ação.”

A noção de cultura e Estado a que está ligado o modelo humboldtiano tinha seu propósito na obrigação deste de subordinar o interesse profissional ao 
espírito crítico-reflexivo. Já a preocupação da universidade napoleônica era com a estabilidade do Estado e, para isso, centralizava as atividades de ensino e as direcionava para produzir as competências profissionais e administrativas necessárias a essa estabilidade.

A oposição entre os dois fortes modelos que teriam influência na estruturação das universidades do mundo ocidental está presente, particularmente no Brasil, no entendimento de como a universidade pode ser uma instituição a serviço do Estado. Enquanto o projeto da Universidade de Berlim desprezava o nacionalismo estreito, o protecionismo, o utilitarismo e o positivismo que guiam os poderes públicos em matéria de ciência, o projeto elaborado e implementado por Napoleão, submetia a universidade a todos os controles do Estado para que ela desempenhasse as atividades desenhadas por este, assegurando os efeitos da ação esperada com vistas ao seu fortalecimento.

O que se tem hoje é um saber mercantilizado, que rompe com a idéia da cultura-Estado, quer relativamente aos fins educativos, espirituais e históricos nacionais de Humboldt, quer com relação aos fins educativos, técnicos e instrumentais nacionais de Napoleão.

Esta situação atual da vinculação do saber com a sociedade instaura uma nova relação - a do saber-provedor com o usuário-consumidor. É um saber produto, uma mercadoria, um investimento, um processo de disputa e valor comercial da informação, ciência e tecnologia, que gera a perda do valor do saber como formador do caráter, da moral, da ética, do espírito reflexivo, do cidadão e da construção da nação.

Dias Sobrinho (2005, p. 122) analisa essa situação, afirmando que, se antes a preocupação era formação integral e a produção de conhecimentos de alto valor civilizatório, hoje a preocupação reside no financiamento e nas questões econômicas. Em suas palavras:

No passado, a universidade foi pensada por intelectuais do peso dos Humboldt, Kant, Fichte, Karl Jasper, Heidegger, só para citar alguns alemães. Hoje, quem diz para os países subdesenvolvidos e em desenvolvimento o que deve ser uma universidade são os economistas e funcionários do Banco Mundial, do BID, do FMI, da OCDE, da COM e, nos âmbitos nacionais, técnicos dos Ministérios da Fazenda e do Planejamento.

Com uma orientação político-econômica determinada pelos princípios neoliberais empregados por grande número de países do mundo ocidental, inclusive o Brasil, o Estado passa paulatinamente a fazer investimentos cada vez menores 
no campo da educação superior e a imprimir uma orientação de “autonomia financeira", desfigurando o conceito clássico de autonomia universitária. A autonomia financeira que o Estado impõe é a de vínculo capitalista que impele as instituições a captarem recursos no mercado, ou seja, é a autonomia financeira da universidade diante do Estado. (PAULA, 2006)

A forma neoliberal de gerir as políticas de educação superior permitiram que o setor privado no Brasil responda hoje por $88 \%$ da oferta das vagas e por $71 \%$ das matrículas, fazendo com que ele seja um dos maiores do mundo (Censo da Educação Superior - INEP/ 2004). Com o auxílio da rede privada, a oferta de vagas para o ensino superior hoje cobre $86 \%$ dos concluintes do ensino médio. No entanto, o Censo da Educação Superior de 2004 demonstra que apenas $10 \%$ dos jovens na faixa de idade de dezoito a vinte e quatro anos a estão freqüentando.

Uma das razões é que o ensino médio não atinge a todos os alunos por insuficiência de vagas no ensino público. Por outro lado, a maior oferta de vagas no ensino superior está na rede privada, o que se tem revelado um erro de enfoque. Segundo o Censo de 2004, a taxa de ociosidade no preenchimento das vagas privadas estava em 49,5\% antes do ProUni, enquanto nas instituições federais é de $0,9 \%$ e, nas estaduais, 4,7\%.

Assim, podemos afirmar que a universidade é uma instituição que - em todos os tempos - sabiamente se coloca em seu tempo, a serviço deste e prospecta o futuro de seu tempo, sem ter vendido a sua alma, ou seja, conservando a função que lhe é própria. Talvez essa seja a sua invencibilidade e talvez seja essa a luta que deverá empenhar hoje, para fazer frente a demandas muito mais díspares, mais imediatas e menos conciliatórias que enfrenta.

Podemos dizer, com Santo Agostinho, que a rigor não há passado, presente e futuro. Há o presente das coisas passadas, o presente das coisas presentes e o presente das coisas futuras. É com esse sentido que devemos discutir as questões da universidade. Não porque ela está atravessando esta ou aquela crise, mas porque as discussões de hoje orientam as atividades a ser programadas com vistas ao preparo contínuo daquelas que futuramente poderão ser desenvolvidas.

\section{A Relação Funcional da Universidade Moderna}

A posse de conhecimentos obtidos de forma organizada nas instituições superiores representou, particularmente no século $\mathrm{XX}$, uma via de entrada num mercado de trabalho seletivo. A perspectiva de mobilidade social através desse nível de educação foi, segundo Schwartzman (1980), uma garantia até a 
década de 1980, quando a expansão do setor industrial, da forma resultante da Revolução Industrial, deu sinais de esgotamento e a indústria informatizada começou a substituir a mão-de-obra pelo emprego de robôs.

A expansão atual do sistema de educação superior não tem sido acompanhada por uma abertura de oportunidades no mercado de trabalho através da criação de novos empregos ou de novas formas produtivas e da ambicionada mobilidade social.

A posse de conhecimentos obtidos no sistema formal da educação superior não mais garante a sonhada vaga de emprego. Hoje, grande número de egressos do sistema de ensino superior forma um contingente de desempregados qualificados. As relações de causa e efeito entre educação e mobilidade social, que ainda preside o imaginário de muitos estudantes e de suas famílias da classe pobre e média, não mais se efetivam.

A relação entre a formação superior e o mercado tem sido discutida em duas vertentes antagônicas: uma vê que o processo de transformação social se dá essencialmente na esfera do sistema produtivo e que os sistemas educacionais se adaptam e se aperfeiçoam para atender às demandas da economia, não tendo, conseqüentemente, força causal própria. A outra atribui à educação uma capacidade de gerar "capital humano" passível, em princípio, da mensuração e da avaliação necessárias para sua utilização racional e de constituir-se em elemento-chave para qualquer processo de desenvolvimento econômico-social (FARO, 1975; LANGONI, 1972). Nossa análise da expansão do sistema de ensino superior brasileiro e da forma como o ProUni está sendo implementado nos leva a acreditar que a atual política de educação está ancorada na segunda vertente e que essa forma de conduzir a abertura de vagas na educação superior está condizente com a direção da política de desenvolvimento do País.

O cenário econômico que estamos vivenciando está demonstrando que os efeitos da democratização educacional não acarretam a democratização social, mas que podem produzir novas e mais dolorosas desigualdades. A educação funcionalista ${ }^{7}$ empreendida, que teve grande eficiência enquanto a universidade mantinha uma relação de correspondência com a necessidade de profissionais dos diferentes setores (administração pública, administração privada, profissionais liberais, profissionais para a indústria e comércio, professores para as escolas, etc.), revela-se perversa para os estudantes e muito benéfica para o mercado.

7 O ideal da educação funcional supõe que deveria haver uma correspondência entre as características de educação dadas pelo sistema de ensino e as atividades para as quais as pessoas se destinam. 
A relação entre massificação da educação superior e visão funcionalista da formação universitária tem colocado anualmente no mercado de trabalho uma quantidade de profissionais muitas vezes superior à necessidade. Esse fato tem levado os postulantes a uma vaga de mercado a uma competitividade extrema e a um processo de seleção cada vez mais exigente, imprimindo a este uma nova característica: cabe ao candidato comprovar a sua "empregabilidade". Por "empregabilidade" hoje se entende todo diferencial que ele possa apresentar e que é visto como vantagem competitiva para ele e para o empregador (domínio de idiomas, conhecimento avançado de informática, experiências, cursos de aperfeiçoamento, estágio no exterior, etc.).

A explicação desse paradoxo só é possível quando nos damos conta de que o que está ocorrendo não é só a disputa acirrada por um número cada vez menor, em termos relativos, de empregos, mas uma progressiva ocupação de vagas, sem exigências de qualificação, por pessoas portadoras de diploma. À medida que a oferta cresce, o diferencial não é mais o valor do título profissional, mas sim as "habilidades e competências agregadas".

As transformações atuais das sociedades, do conhecimento, da economia, das políticas tornam praticamente impossível prever e proporcionar aos estudantes não só a formação, como os conhecimentos que lhes serão necessários quando formados e em atividade profissional. Se essa dificuldade ocorre do ponto de vista do conhecimento, ela é ainda mais séria do ponto de vista da especialização precoce que se faz na graduação. Não há como preparar adequadamente as capacidades que serão requeridas para os diversos tipos de profissionais do mercado futuro. A universidade, na visão de democratização da educação superior e no atendimento a uma educação de massa, terá que novamente discutir se a formação universitária deve ser entendida e oferecida como um bem válido em si mesmo, tanto para o indivíduo como para a sociedade, ou se deve continuar atrelada a uma formação específica direcionada para um efêmero mercado.

É ainda Schwartzman (1980, p. 12) que alerta para não esquecermos que a educação superior, em suas diversas formas, pode pouco diante de questões mais gerais da sociedade: "Os problemas da pobreza, do desemprego, da ignorância, da alienação, dependem de soluções a nível econômico, político e administrativo que não poderiam ser adiadas sob o pretexto de que, com a educação, eles se resolveriam naturalmente.” 


\section{A Universidade Moderna em Tempos Atuais}

Na análise de Touraine (1994), nesse contexto de implantação de um Estado neoliberal, retomam-se, de forma reacionária e exacerbada, princípios liberais que nortearam processos revolucionários do século XVIII. Compartilhando com outros críticos a forma de analisar a situação atual, Touraine desvela a inconsistência de paradigmas teórico-práticos originados no período iniciado pela Renascença, representados pelo pensamento filosófico de Descartes, pelo empirismo de Bacon e consubstanciados pelo Iluminismo, expressos principalmente pelas idéias de Rousseau e de Kant.

A modernidade, que demarcou as fronteiras dos Estados nacionais, que apontou possibilidades emancipatórias através de uma produção social e que instaurou as bases da ciência sobre a objetividade, a neutralidade, o desinteresse e a validade da experimentação, tem agora nova análise que interpreta que seus alicerces basilares estão abalados por três ordens de fatores: pela globalização da economia, a qual redesenha o território e o papel do Estado; pelas políticas neoliberais, que transferem o direito de cidadania para a "liberdade de mercado"; e por uma produção científico-tecnológica cada vez mais concentradora e excludente.

A forma de entender o papel e a função da universidade, na análise de Velho (1999, p. 135), faz "as fronteiras entre a universidade e o setor produtivo se fluidificarem na geração da fábrica do conhecimento". Ele também expõe haver uma nova raiz que determina a universidade atual e que a liga com a sociedade e o setor produtivo através da busca de solução para os seus problemas. É uma visão da universidade como empreendedora e berço de empresas de cunho tecnológico. Essa relação, representada pela interação universidade-empresa, é a representação mais acabada da universidade vista como fábrica de conhecimentos e longe de ser a universidade pensada como formação do ser humano. A lógica da tendência utilitarista da universidade tende a reduzir a construção do conhecimento a mera produção de conhecimento mercadológico.

Reflexos dessa visão têm se concretizado na intenção curricular das atuais universidades e na dinâmica da formação dos estudantes. A prática do incentivo ao desenvolvimento das empresas juniores, como uma atividade de ponta na formação de profissionais empreendedores, é um exemplo de como se justificam as funções da universidade submetida aos ditames das "necessidades" sociais. As incubadoras de empresas nascendo dentro dos muros universitários, por mais significantes que possam ser para os alunos, para as empresas e para a própria universidade, representam a materialização da relação unívoca da 
universidade com o setor produtivo. Na busca de melhor inserção social, os currículos prontificam-se a formar profissionais pragmáticos e melhor "adaptados" a essas necessidades.

É comum também vermos alunos que, desde os primeiros anos de seu curso de graduação, já trabalham na direção de sua monografia de final de curso, tendo nesse trabalho a perspectiva de desenvolver um projeto de mestrado sob o mesmo tema. Isto mostra a precipitação de uma especialização e revela que esses alunos estão fazendo uma trajetória em busca de uma individualizada forma de gerir o seu papel social.

Para Readings (1996), tentar fazer a universidade hoje enveredar por caminhos de uma reconstituição utópica das grandes narrativas e de restaurar harmonias perdidas, é um anacronismo voltado ao fracasso. Em suas análises o autor provoca os que se dispõem a pensar a universidade para que assumam o desconforto da situação para reinventar o seu papel sem desalentos paralisantes e sem encantos ilusórios. Readings diz não pensar que se exige hoje a edificação de uma nova instituição com um modelo de eficiência ou um projeto unificado e unificador. Para ele, a universidade deste período, que se pode chamar de um período pós-moderno, não tem uma função ideológica unificadora, particularmente por não ter a função de unificar um povo através de uma cultura nacional.

\section{Considerações Finais}

O projeto da universidade moderna se estruturou de forma a ser diferente de tudo o que se constituía universidade até aquele tempo. $\mathrm{O}$ caráter inovador dado a essa instituição pode ser verificado no projeto de Humboldt cujo conceito de universidade implicou essencialmente as tarefas de promoção do desenvolvimento máximo da ciência e de produção do conteúdo responsável pela formação intelectual e moral da Nação.

Os princípios traçados por ele estabeleceram-se como aqueles que toda universidade deveria sustentar para o bem público e o da nação. O projeto de universidade que, ao mesmo tempo, se adequava ao novo tempo e se projetava para além dele, teve grande influência no mundo ocidental, notadamente nas universidades européias, norte-americanas, canadenses e australianas. Embora com pouca existência conforme planejado, paradoxalmente, este projeto é a referência mais difundida e defendida de universidade na modernidade.

Os princípios essenciais postulados e defendidos até hoje, como formulações que dão à universidade seu caráter próprio, não se alteraram na sua essência. 
Apesar de ser uma forte referência, o modelo alemão não foi o único entre as universidades do mundo ocidental que se constituíram como instituição da modernidade. Há os modelos da universidade inglesa e o da universidade francesa e a dos países socialistas (caracterizados como modelos funcionalistas).

Hoje, acreditamos que a luta pela autonomia, aspecto primordial do projeto humboldtiano, seja ainda mais decisiva em qualquer país, por envolver a busca de autonomia em relação a interesses de toda sorte: econômicos, políticos, corporativos (de docentes e discentes); de grupos locais e regionais; de grupos nacionais e internacionais; de grupos minoritários ou excluídos; e até mesmo de área e disciplina. O limiar entre a autonomia e a defesa de interesses internos e externos à universidade é tênue.

A crise da universidade moderna é vista como sendo gerada na tensão problemática de domínios de contradição na visão de Santos (1994) e de dimensões como a conceitual, a contextual, a financeira, a de modelo, a de elitismo, a de objetivos e a de metas, na visão de outros analistas.

A situação atual da vinculação do saber com a sociedade instaura uma nova relação - a do saber-provedor com o usuário-consumidor. É um saber produto, uma mercadoria, um investimento, um processo de disputa e valor comercial da informação, ciência e tecnologia, que gera a perda do valor do saber como formador do caráter, da moral, da ética, do espírito reflexivo, do cidadão e da construção da nação.

No Brasil, são poucas hoje as instituições universitárias voltadas para o ensino e pesquisa. Essa vinculação é defendida por universidade que não se colocam como finalidade o atendimento às necessidades do mercado ou às estreitas necessidades da sociedade. A forma neoliberal de gerir as políticas de educação superior permitiu que o setor privado no Brasil fosse hoje predominante em termos de ofertas de vagas. A forma de entender o papel e a função da universidade, na análise de Velho (1999, p. 135), faz "as fronteiras entre a universidade e o setor produtivo se fluidificarem na geração da fábrica do conhecimento". É uma visão da universidade como empreendedora e berço de empresas de cunho tecnológico e a lógica da tendência utilitarista da universidade tende a reduzir a construção do conhecimento a mera produção de conhecimento mercadológico.

No presente tempo, que podemos caracterizar como sendo um período histórico que ultrapassa os determinantes da forma de produzir conhecimento da época moderna, a universidade da contemporaneidade não tem uma função ideológica unificadora e nem deve ser pensada como um modelo de eficiência ou como um projeto unificado e unificador, mas ser pensada de forma a ser uma 
nova instituição para a cultura atual e para a nova forma de produzir conhecimento. Uma forma menos racionalista e finalista e mais holístico e humana.

\section{Referências}

BRASIL. Congresso Nacional. Lei de Diretrizes e Bases da Educação Nacional. Lei $\mathbf{n}^{\circ}$ 9394/96, de 20 de dezembro de 1996. Estabelece as Diretrizes e Bases da Educação Nacional. Brasília, DF, 1996.

CASPER, G. Um mundo sem universidades? In: CASPER, G; HUMBOLDT, W. Um mundo sem universidades? Rio de Janeiro: EdUERJ, 1997.

DIAS SOBRINHO, J. Dilemas da educação superior no mundo globalizado: sociedade do conhecimento ou economia do conhecimento? São Paulo: Casa do Psicólogo, 2005.

DRÉZE, J.; DEBELLE, J. Concepções da universidade. Fortaleza: EdUFCE, 1983.

FARO, C. Taxas de retorno dos investimentos em educação no Brasil. Revista Brasileira de Economia, Rio de Janeiro, v. 29, n. 3, p. 89-108, jul. 1975.

GOERGEN, P. L. Prefácio. In: DIAS SOBRINHO, J. Dilemas da educação superior no mundo globalizado: sociedade do conhecimento ou economia do conhecimento? São Paulo: Casa do Psicólogo, 2005.

HUMBOLDT, W. Sobre a organização interna e externa das instituições científicas superiores em Berlim. In: CASPER, G.; HUMBOLDT, W. Um mundo sem universidades? Rio de Janeiro: EdUERJ, 1997.

KANT, I. Conflito das faculdades. Lisboa: Edições 70, 1993.

KERR, C. Os usos da universidade. Fortaleza: EdUFCE, 1982.

LANGONI, C. G. A rentabilidade social dos investimentos um educação no Brasil. Rio de Janeiro: ANPEC, 1972.

LYOTARD, J. F. A condição pós-moderna. Lisboa: Gradiva Publicações, 1989.

PAULA, M. F. As propostas de democratização do acesso ao ensino superior do governo Lula: reflexões para o debate. Avaliação. Campinas; Sorocaba, v. 11, n. 1, p. 133-147. mar. 2006. 
READINGS, B. Universidade sem cultura? Rio de Janeiro: EdUERJ. 1996.

RISTOFF, D. A tríplice crise da universidade brasileira, in: TRINDADE, H. (org), Universidade em ruínas na república dos professores. Petrópolis, RJ: Vozes, 1999.

ROCHA, J. C. C. Respostas à pergunta: que é universidade? In: CASPER G.; HUMBOLDT, W. Um mundo sem universidades? Rio de Janeiro: EdUERJ, 1997.

SANTOS, B. S. Da idéia de universidade a universidade de idéias. In:

Pela mão de Alice: o social e o político na pós-modernidade. Porto: Afrontamento, 1994. p. 187-226

SCHWARTZMAN, S. Ciência, universidade e ideologia: a política do conhecimento. Rio de Janeiro: Zahar, 1980.

THAYER, Willy. La crisis no moderna de la universidade moderna. Santiago do Chile: Ed. Cuarto Próprio, 1996.

TOURAINE, A. Critique de la modernité. Paris: Livres de Poche, 1994.

TROW, M. Problems in the transition from elite to mass higher education. In: CONFERENCE OF FUTURE STRUCTURES OF POST-SECONDARY EDUCATION, Paris, 1973. Policies for higher education, general report. Paris: OCDE, 1973.

VELHO, G. Universidade e pluralismo sociocultural. In: OLINTO, H. K.; SCHOLLHAMMER, K.E. Novas epistemologias: desafios para a universidade do futuro. Rio de Janeiro: Ed. NAU; PUC-Rio, 1999. 